\title{
Dossiê
}

\begin{tabular}{l} 
REsumo \\
Aopartirmos da noção de que \\
osprimeiros gestos espontâneos \\
e criativos do bebê revelam \\
aspectos importantes da quali- \\
dade de suas primeiras relações \\
precoces com o objeto materno, \\
bem como de seu processo de \\
adaptação ao ambiente dito \\
suficientemente bom, pode- \\
mos presumir que o brincar \\
primitivo do bebê possui um \\
importante papel de sinaliza- \\
dor de sofrimento psíquico. Por \\
meio de um estudo longitudinal \\
de bebês com risco de autismo \\
acompanhados entre os 6 meses \\
e 3 anos, pôde-se constatar que \\
a maneira como esses bebês ex- \\
ploram, interagem e respondem \\
a um brincar compartilhado \\
com o outro se diferencia sig- \\
nificativamente da de bebês \\
que apresentam um atraso do \\
desenvolvimento psicomotor, \\
sem traços de risco de autismo, \\
e de bebês saudáveis (normais). \\
Descritores: brincar preco- \\
ce; brincar simbólico; autismo; \\
intervenção precoce. \\
\hline
\end{tabular}

\section{O BRINCAR PRECOCE DO BEBÊ COMO \\ INDICADOR DE RISCOS DE SOFRIMENTO PSÍQUICO}

\section{Camila Saboia}

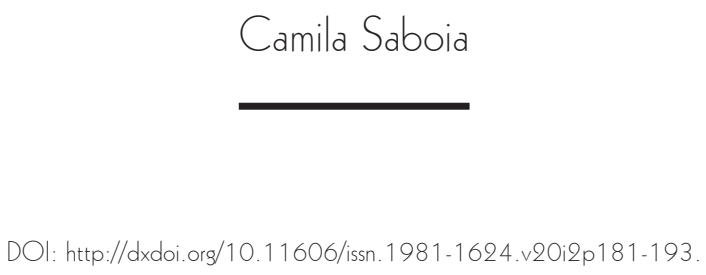

brincar do bebê poderia sinalizar possíveis entraves no processo de seu desenvolvimento psicoafetivo? Em que medida a expressão da qualidade do brincar do bebê nos conta algo de sua adaptação ao mundo? Se considerarmos que as primeiras manifestações do brincar revelam elementos associados ao grau de maturação psíquica do pequeno infans, o que pensar, então, dos comportamentos de certos bebês que desde muito cedo se recusam a explorar os

Psicóloga e psicanalista. Doutora pela Universidade de Paris 7. Pós-Doutoranda do Instituto de Psicologia da Universidade de São Paulo (IPUSP). Membro do Lugar de Vida Centro de Educação Terapêutica, São Paulo, SP, Brasil. 
objetos externos do ambiente quando "investidos" e apresentados pelo adulto familiar?

Essas perguntas parecem importantes ao abordarmos o trabalho no campo da intervenção precoce - fundamentado na ideia de sensibilizar os profissionais da primeira infância aos sinais de riscos de sofrimento psíquico do bebê, que se revelam na capacidade de interagir com o adulto familiar, seja por meio de suas expressões corporais, seja mediante suas produções vocálicas, seja ainda pela produção de gestos espontâneos e criativos naquilo que consideramos como o brincar precoce ou primitivo do bebê, cuja função é de importância fundamental no processo de construção da realidade psíquica da criança.

Quando nos referimos à existência de um brincar precoce ou constitutivo do bebê, presente desde os primeiros meses de vida da criança, somos levados a evocar a noção do bebê como aquele que exerceria um papel "ativo" no processo de acesso à intersubjetividade. Isso implicaria abandonar a ideia preconizada até então de que o bebê teria pouca participação no seu processo subjetivo - de que seu papel se resumiria ao ato de nutrir-se, dada sua vida mental limitada e de pouca relevância.

No entanto, pesquisas desenvolvidas nos últimos anos sobre o comportamento dos bebês com sua mãe apontam na direção contrária: afirmam, por exemplo, que os bebês são suficientemente competentes para estabelecer contato com o outro, graças ao que chamamos de Intersubjetividade Primária (Trevarthen, 1979), conceito que preconiza a ideia de que o bebê, desde os primórdios, seria apto a convocar e, mesmo, provocar (Nagy \& Molnar, 2004) ${ }^{1}$ o adulto familiar a fim de que uma relação a dois se estabeleça.

Do ponto de vista winnicottiano, podemos associar o conceito de Intersubjetividade Primária ao de Potencial Herdado (Winnicott 1942/1972), uma vez que esse último fundamenta-se na ideia de que os bebês já chegam ao mundo com uma capacidade precoce de desempenhar um papel ativo no processo de sua construção subjetiva, o que implicaria considerar o fato de que os bebês carregariam consigo mensagens e conteúdos próprios, que se revelariam no encontro com a mãe dita suficientemente boa.

Winnicott postula que esse encontro inicial do bebê com sua mãe seria regido por meio do jogo primitivo intitulado playground (Winnicott, 1971/1975), o qual ele define como uma expressão do brincar precoce do bebê que corresponderia, na realidade, a uma

182 Estilos clin., São Paulo, v. 20, n. 2, mai./ago. 2015, 181-193. 
protorrepresentação do Espaço Potencial - isto é, a um esboço do Espaço Transicional ou da zona intermediária, na qual a mãe não somente se apresentaria como objeto especular, mas também introduziria à criança objetos concretos e reais do ambiente (Winnicott, 1963/1970). É por esse viés que podemos inferir que para Winnicott, a construção da relação objetal seria marcada, sobretudo, pela qualidade da interação com os objetos reais do ambiente. Dito de outra forma, para ele seria através das experiências sensoriais e táteis que os bebês passariam a organizar e a elaborar suas primeiras experiências precoces com o objeto maternal.

Poderíamos, assim, presumir que os primeiros gestos espontâneos e criativos dos bebês, sendo estes manifestados já nas primeiras interações dos bebês com os objetos reais do ambiente, seriam carregados de conteúdos próprios ou de protossignificantes, os quais revelariam o grau de maturação psicoafetiva da criança. Em outras palavras, diríamos que o interesse do bebê em relação ao objeto que lhe é apresentado (object-presenting) - sua curiosidade e seu interesse em manipulá-lo ou em explorá-lo - estaria intrinsecamente associado à qualidade de suas relações precoces com o objeto materno, que, por sua vez, traduziria seu grau de adaptação ao ambiente dito suficientemente bom.

É com base nessa perspectiva que Winnicott (1968/1989) parece reconsiderar sua teoria da construção 
da relação objetal ao introduzir a ideia de que o processo de subjetivação da criança se estabeleceria graças a sua capacidade de utilizar os objetos do ambiente (object-usage) de maneira criativa e simbólica. No entanto, ele enfatiza que, para que a criança aceda à zona da criatividade, será necessário, primeiramente, que ela estabeleça uma "relação de objeto" (object-relating) com o objeto primário - a mãe suficientemente boa que, por conseguinte, perderia gradativamente seu lugar de objeto primordial, dando espaço para o surgimento do objeto transicional, o qual proporcionaria à criança o sentimento de uma continuidade entre ela e o objeto.

Contudo, na experiência clínica com crianças autistas observamos justamente uma ausência dessa transição: constatamos uma tendência delas de permanecerem "coladas" aos objetos na medida em que suas explorações são predominantemente marcadas por ações repetitivas e estereotipadas, e não por produções simbólicas. Tal fato explicaria a presença de objetos autísticos, que surgiriam como uma tentativa da criança de suprir ou amenizar a perda violenta ou brusca do objeto primário. Esse sentimento, a nosso ver, estaria intrinsecamente associado ao processo de transição vivido pelo bebê entre o brincar primitivo (playground) e o brincar simbólico (playing), que, por sua vez, estaria ligado à passagem entre o modo de relação de objeto e o modo de utilização de objeto. Nesse sentido, vale a pena questionar se a incapacidade das crianças autistas de estabelecer uma relação simbólica com os objetos externos do ambiente não se daria, precisamente, por uma provável falha no processo de transição entre esses dois modos de relação de objeto a que Winnicott se refere.

Partindo desse referencial teórico e das observações de bebês e crianças que apresentavam traços autísticos associados à presença da Síndrome de West, fundamentamos nossa pesquisa sobre indicadores de riscos de autismo que pretendemos expor neste artigo. Sobre a Síndrome de West, é importante ressaltar que se trata de um espasmo infantil ou um tipo de epilepsia precoce, manifestado nos primeiros anos de vida da criança, cuja evolução para um quadro de patologia autística pode apresentar uma incidência de 7 a 33\%.

A pesquisa em questão tinha como objetivo principal analisar a construção do brincar simbólico dessas crianças a fim de constatar o grau de correlação entre o brincar precoce do bebê e o brincar simbólico da criança por meio de um estudo longitudinal entre os 6 meses e os 3 anos. Em outras palavras, nosso intuito era identificar se a qualidade das primeiras manifestações das expressões do brincar do bebê seria, efetivamente, relevadora de traços de um quadro de patologia autística em curso ou em desenvolvimento na criança pequena.

Vale ressaltar que esta pesquisa foi desenvolvida no âmbito de uma pesquisa maior intitulada Programa 
Internacional pela Linguagem da Criança (PILE) ${ }^{2}$, cujo propósito era estudar os elementos corporais e interativos precursores da linguagem verbal das crianças a partir de cinco vias complementares: interativa, do desenvolvimento, psicodinâmica, do apego e psicopatológica. A metodologia da pesquisa PILE baseava-se em estudar de maneira minuciosa a qualidade das trocas interativas de bebês, com idades de 3 meses a 4 anos, com sua mãe. Esses bebês, considerados com sinais de risco de sofrimento psíquico, eram divididos em diferentes grupos (prematuros, de mãe cega, hospitalizados, com distúrbios alimentares precoces e portadores de Síndrome de West $\left.^{3}\right)$. A dupla mãecriança era filmada numa pequena sala de vídeo, devidamente adaptada com um sistema de multicâmeras capaz de fornecer imagens precisas do movimento do corpo, do olhar, bem como da qualidade das produções vocálicas dos bebês, os quais seriam estudados por meio do protocolo denominado de Transat (cadeira infantil que lembra aquela que chamamos de "bebê conforto").

Este protocolo, criado especificamente para as análises do comportamento do bebê de 3 a 9 meses, era composto por três momentos distintos que duravam três minutos cada: nos primeiros três minutos, a mãe interagia livremente com a criança (sequência interação livre); no segundo momento, ela lhe apresentava um objeto (sequência girafa
Sophie ${ }^{4}$ ); nos três minutos finais, ela cantava para o filho, estimulando-o com os movimentos de suas mãos, que acompanhavam o ritmo da canção (sequência canção $0^{5}$ ).

Dos 9 meses aos 4 anos, as análises das sequências de filmes da díade mãe-bebê eram realizadas a partir de um novo protocolo, chamado de Tapis rouge (tapete vermelho). Este se caracteriza por uma situação de observação de jogo da criança, que era convidada a brincar com sua mãe de maneira livre e espontânea com diversos brinquedos dispostos sobre o tapete durante 20 minutos. Além disso, as crianças também eram avaliadas por meio de outros testes psicológicos, os quais permitiam estudar o desenvolvimento delas a partir de diferentes aspectos - testes como CIB, Brunet-Lézine, WWPSI, Mac-Arthur, Entretien-R, MalletteProjective, Histoire à Completer, Autismo PREAUT, CARS, ADI, entre outros.

Como nosso objetivo era estudar os aspectos associados ao autismo precoce, privilegiamos o grupo de bebês com Síndrome de West, uma vez que sabemos que esses bebês podem apresentar, no decorrer de seu desenvolvimento, possíveis traços de uma organização autística. Optamos por estudar os bebês a partir da idade de 6 meses, pois sabemos que é nesse momento do desenvolvimento do bebê que ele passa a interessar-se mais pelos objetos inanimados, principalmente quando investidos por sua mãe ou 
pelo adulto familiar, lançando-se de maneira mais espontânea num brincar a dois (Stern, 1985/2006).

Nossa hipótese de trabalho, na qual o brincar precoce poderia ser visto como um sinalizador de possíveis entraves no processo constitutivo do bebê, foi formulada ao constatarmos que dos 23 bebês que constituíam o grupo Síndrome de West, 5 apresentavam traços de risco de autismo ${ }^{6}-$ mostravam, desde a idade precoce de 6 meses, um desinteresse significativo no que dizia respeito à exploração e à manipulação dos objetos oferecidos pelo adulto. Observamos, por exemplo, que na cena do protocolo Transat, na qual a mãe interagia com a criança na presença de um objeto - a girafa Sophie -, estas crianças não procuravam direcionar-se ao brinquedo, da mesma maneira que não tentavam agarrá-lo e muito menos explorá-lo, recusando-se a responder ao convite de um brincar compartilhado proposto por sua mãe. Por outro lado, tais comportamentos não foram observados nos bebês com Síndrome de West, que apresentavam um atraso no desenvolvimento marcado por um déficit psicomotor segundo a escala Brunet-Lèzine, mas com ausência de traços de risco de autismo, e tampouco no comportamento de bebês do grupo controle, constituído por bebês saudáveis. É importante salientar que dos 5 bebês diagnosticados com risco de autismo, todos foram encaminhados, por volta dos 6 meses, para serviços especializados em atendimento 
de intervenção precoce; 3 deles tiveram o diagnóstico de autismo confirmado aos 3 anos pelas escalas Childhood Autistic Rating Scale (CARS) e Autism Diagnostic Interview (ADI).

Além disso, verificamos que aqueles mesmos bebês tendiam a retrair-se quando solicitados por sua mãe. Por exemplo: por meio da análise da escala Coding Interactive Behaviour (CIB) (Feldman, $1998)^{7}$, notamos que esses bebês eram sensíveis à presença do objeto apresentado por sua mãe, mas tendiam a fixar seu olhar, sistematicamente, na direção oposta à do objeto. Percebemos, também, uma alta frequência de respostas como withdrawal (retraimento) e um baixo índice de respostas como involvement (engajamento, envolvimento).

Porém, ressaltamos que aos 6 meses, curiosamente, a qualidade de investimento da relação materna desses bebês com risco de autismo era comparável à das mães do grupo West com atraso psicomotor, e até mesmo do grupo controle. Já aos 9 meses constatamos uma mudança significativa desse quadro: as mães do grupo dessas crianças pareciam menos presentes nos momentos de trocas interativas com seus bebês. Tal comportamento foi revelado por uma queda considerável do indicador sensitivity da escala CIB, sinalizando uma diminuição da qualidade de interação entre a dupla mãe-bebê, manifesta, por exemplo, na ausência de picos prosódicos e também de mamanhế $\hat{s}^{8} \mathrm{em}$ sua fala. Ademais, observamos que elas passavam a convocar a criança de uma maneira um tanto invasiva, colocando o objeto girafa muito próximo ao seu rosto, numa espécie de tentativa desesperada de chamar sua atenção a todo custo.

Vale aqui questionar se esta alteração no comportamento materno, entre o sexto e o nono mês de vida do bebê ocorreu em decorrência das dificuldades deste último em responder aos apelos e investimentos da mãe.

Aos 9 meses, essa recusa do bebê em responder à convocação materna torna-se mais evidente: notamos a ausência de protoconversações entre a dupla, bem como um comprometimento da atenção compartilhada dessas crianças - elas, por exemplo, não acompanhavam com o olhar o objeto girafa apresentado pela mãe.

Se tais crianças, aos 6 meses, não exploravam os objetos com a boca, aos 9 meses, passavam a examiná-los de maneira rápida e fugaz, assinalando sua dificuldade de investir e explorar os objetos externos do ambiente (no caso, a girafa). Observamos, graças a um estudo microscópico das análises interativas desses bebês com sua mãe $e^{9}$ uma mudança significativa quanto à exploração oral do objeto; 
agora, eles passavam a investir e explorar a girafa oralmente, embora tal exploração fosse marcada por uma extrema pobreza e rapidez, que se limitava a uma duração de no máximo um segundo, enquanto que com os bebês do grupo controle essa duração poderia se estender por até quatro segundos, de acordo com a leitura indicada pelo software ELAN. Esse dado sugere uma insensibilidade desses bebês à zona erógena da região bucal, o que seria um sinalizador de sofrimento psíquico, uma vez que sabemos que o investimento oral-pulsional da criança em relação aos objetos desempenha um papel importante no processo da constituição de sua realidade psíquica.

Outro ponto interessante observado no decorrer do estudo do comportamento de bebês West com riscos de autismo refere-se à qualidade de sua atenção. Pesquisas recentes sobre autismo precoce enfatizam que os bebês diagnosticados com riscos de autismo não são completamente indiferentes à presença do adulto familiar, bem como à presença de objetos inanimados quando estes são "investidos" ou "animados" por este adulto. Assim, enquanto função primária, a atenção do bebê autista não estaria comprometida, mas apenas enquanto função social (Maestro \& Muratori, 2002). Tal fato explicaria a razão pela qual esses bebês veem, mas não olham, já que olhar demanda, de fato, uma maior sensibilidade à interação com o outro, bem como à percepção dos objetos externos do ambiente.

Nossa pesquisa parece ilustrar essa hipótese ao constatar, por exemplo, que os bebês do grupo com risco de autismo direcionavam seu olhar ao objeto girafa com duração inferior a cinco segundos em relação aos bebês saudáveis. Este dado parece sinalizar a dificuldade do bebê autista em "sustentar" seu olhar ao de sua mãe - o que difere da leitura simplista que categoriza o bebê autista como aquele que se recusa, de forma absoluta, a entrar em contato com o olhar do outro. $\mathrm{Na}$ idade de 9 meses, essa dificuldade parecia acentuar-se: observamos uma maior discrepância entre os dois grupos - agora os bebês autistas sustentavam seu olhar no objeto girafa por, no máximo, quatro segundos, enquanto os do grupo controle o faziam por doze segundos.

No decorrer da pesquisa, pudemos verificar que a dificuldade desses bebês em explorar o brinquedo girafa - em resposta ao convite de um jogo interativo com sua mãe - parecia, de fato, ser um indicador de uma dificuldade futura da criança de se engajar na produção de um brincar simbólico. Tal hipótese foi constatada quando avaliamos o brincar dos bebês do grupo West com risco de autismo na idade

Estilos clin., São Paulo, v. 20, n. 2, mai./ago. 2015, 181-193. 
de 15 meses $^{10}$ : notamos que essas crianças recusavam-se a explorar os objetos disponíveis no tapete de jogo; muitas vezes recorriam à exploração dos objetos da sala de filmagem ao mesmo tempo que preferiam permanecer rodopiando nos cantos da sala.

Quando solicitávamos diretamente sua atenção, poucas vezes elas nos respondiam, negando-se a explorar os objetos do jogo, além de se mostrarem indiferentes à presença da mãe e do terapeuta. Isto diferia das crianças West com atraso psicomotor sem traços de autismo, pois apesar da dificuldade de se deslocar, estas buscavam explorar os objetos do jogo com grande interesse e curiosidade, solicitando a ajuda de um adulto quando necessário.

Aos 24 meses observamos que as crianças do grupo autista passavam a se interessar em explorar os objetos do tapete de jogo, embora de maneira pobre e estereotipada - as explorações eram feitas sem intencionalidade, ou seja, sem que houvesse, de fato, a presença de um investimento pulsional em relação a esses objetos. A criança, por exemplo, pegava o patinho de borracha e o esfregava com movimentos repetitivos sobre o tapete do jogo; em seguida, de maneira aleatória, pegava outro brinquedo para manipulá-lo de forma mecânica. Por volta dos 30 meses, constatamos um maior investimento das crianças em relação aos objetos, na medida em que agora elas os exploravam oralmente. A presença de exploração de caráter oral sugere uma 
apropriação da zona erógena da região bucal no processo da construção da imagem corporal dessas crianças. Em outras palavras, é como se a sua relação com os objetos externos do ambiente passassem de um estatuto "ana-objetal" para “objetal”, uma vez que agora era possível observar uma verdadeira intencionalidade, por parte da criança, em lançar-se na exploração dos objetos do jogo, mesmo que por vezes elas fossem realizadas de forma estereotipada. O que nos levaria a supor que, para a criança autista, a única forma de estabelecer e sustentar uma relação eu-mundo externo seria, talvez, por intermédio da presença dos objetos autísticos.

Em seguida, por volta dos 36 meses, notamos que as crianças que se mostravam mais organizadas psiquicamente, tanto no que diz respeito à sua referência espaço-temporal como em relação à construção de sua imagem corporal, manipulavam os objetos do jogo de maneira mais rica e detalhada por meio de explorações sonoras - elas, por exemplo, pegavam os objetos e os batiam uns contra os outros num movimento ritmado, na busca de produzir sons. É interessante destacar que esses comportamentos parecem ilustrar a ideia preconizada por Maiello (1998), segundo a qual a construção da relação objetal da criança se daria graças às experiências regidas pelo ritmo e pela musicalidade entre o bebê e seu mundo.

Para concluir, observamos que os bebês, que desde um tempo precoce 
de seu desenvolvimento - 6 meses de idade - recusavam-se a entrar em contato com o outro, que se negavam a lançar-se na exploração do objeto externo apresentado e investido pelo outro familiar (a mãe, neste caso), apresentavam, com 9 meses, um comprometimento de sua atenção compartilhada, o que indicaria possíveis entraves no processo de sua construção simbólica. Convém ressaltar que o desinteresse dos bebês West com traços autísticos em explorar o objeto girafa não decorria, necessariamente, de problemas relacionados a um possível atraso psicomotor, uma vez que se constatou que os bebês West com déficit psicomotor respondiam, facilmente, à proposição do brincar compartilhado - tentavam agarrar o objeto girafa para manipulá-lo e explorá-lo, ultrapassando, por vezes, suas limitações físicas.

É nesse sentido que concluímos que a qualidade do brincar precoce do bebê é sem dúvida um sinalizador de possíveis entraves no processo constitutivo do bebê, na medida em que pudemos verificar, ao longo desse estudo, que os resultados associados à analise do brincar primitivo do bebê são diretamente ligados àqueles referentes ao brincar simbólico da criança.

THE EARLY PLAY OF THE BABY AS AN INDICATOR OF RISK OF PSYCHICAL DISTRESS

\section{Abstract}

Using the notion that the first spontaneous and creative gestures of babies reveal important aspects of the quality of their first early relationships with the maternal object, as well as their process of adaptation to an environment considered as good enough, we can assume that the primitive play of babies has an important role to identify psychical distress. Through a longitudinal study of infants showing risk of autism, followed between 6 months and 3 years, we could find that the way these babies explore, interact and respond to a shared play with others significantly differ from babies who have a developmental delay without autistic traits, and healthy (normal) babies.

Index terms: early play; symbolic play; autism; early intervention.

EL JUEGO PRECOZ DEL BEBÉ COMO INDICADOR DEL RIESGO DE SUFRIMIENTO PSÍQUICO

\section{Resumen}

Si tomamos la noción de que los primeros gestos espontáneos y creativos del bebé aparecen aspectos importantes de la calidad de sus relaciones precoces con el objeto materno, asi como el proceso de adaptación a un medio considerado suficientemente bueno, podemos suponer que estos juegos primitivos del bebé tienen un rol importante en la identificación del sufrimiento psíquico. A través de un estudio longitudinal con bebés que presentaban evidencias de riesgos autistas, seguidos entre los 6 meses hasta los 3 años de edad, mostró una diferencia significativa en la manera como estos exploran, interactuan y responden al juego con otros, en comparación con los que presentan un retardo en el desarrollo psicomotor, sin rasgos autistas, y con los de desarrollo normal.

Palabras clave: juegos primitivos, juego simbólico, autismo, intervención temprana.

\section{REFERÊNCIAS}

Feldman, R. (1998). Coding interactive behavior manual. Texto não publicado.

Laznik, M.-C. (2006). Préaut: une recherche et une clinique du très précoce. Comment passer de ces bébés qui troublent leurs parents à des petits qui auraient plaisir à 
s'amuser avec eux. Contraste: enfance et handicap, 25, 53-80.

Maestro, S., \& Muratori, F. (2002). Autisme: les films familiaux. Le Carnet/PSY, 75, 35-36.

Maiello, S. (1998). Trames sonores et rythimiques primordiales: reminiscences auditives dans le travail psychanalytique. Compte rendu du GERPEN, 39, 2-24.

Meltzer, D., Bremner, J., Hoxter, S., Weddell, D., \& Wittenerg, I. (1980). Explorations dans le monde de l'autisme. Paris, França: Payot.

Nagy, E., \& Molnar, P. (2004). Homo imitans or homo provocans? The phenomenon of neonatal imitation. Infant behaviour and development, 27(1), 54-63. doi:10.1016/j. infbeh.2003.06.004

Roman, P. (2005). La Mallette Projective Première Enfance (MPPE): un outil clinique pour l'évaluation de la personnalité du jeune enfant. Devenir, 17(3), 233-259.

Trevarthen, C. (1979). Communication and cooperation in early infancy: a description of primary intersubjectivity. In M. Bullowa (Ed.), Before speech: the beginning of human communication (pp. 321-347). Londres, Inglattera: Cambridge University Press.

Winnicott, D. W. (1970). De la communication et de la non-communication. In D. W. Winnicott, Processus de maturation chez l'enfant: développement affectif et environnement (J. Kalmanovitch, trad., pp. 151-168). Paris, França: Payot. (Trabalho original publicado em 1963)

Winnicott, D. W. (1972). Pourquoi les enfants jouent-ils? In D. W. Winnicott, L'enfant et le monde extérieur (A. Stronck-Robert, trad., pp. 123-127). Paris, França: Payot. (Trabalho original publicado em 1942)

Winnicott, D. W. (1975). Jeu et réalité (C. Monod \& J.-B. Pontalis, trads.). Paris, França: Gallimard. (Trabalho original publicado em 1971)

Winnicott, D. W. (1989). On the use of an object. In D. W. Winnicott, Psycho-analytic explorations (pp. 217-246). Londres,
Inglaterra: Karnac. (Trabalho original publicado em 1968)

\section{NOTAS}

1. Essa dupla de pesquisadores húngaros verificou que os bebês não somente eram aptos a imitar os comportamentos dos adultos, devido à existência dos neurônios espelhos, como também seriam eles os responsáveis pela troca de contato com o outro familiar - o pequeno infans tenderia a convidar o adulto a dar continuidade a uma relação de interação, de encontro entre dois sujeitos.

2. O programa de pesquisa internacional PILE foi fundado em 2004 por Bernard Golse e Valèrie Desjardins no Serviço de Psiquiatria Infantil do Hospital Necker - Enfants Malades, Paris, França.

3. Esse grupo de bebês era dirigido pela neuropediatra Lisa-Ouss, atual diretora do projeto PILE.

4. Um brinquedo em forma de girafa, que emite sons ao ser balançado pelo bebê. Este brinquedo, chamado girafa Sophie, é bastante familiar aos bebês franceses.

5. O movimento ritmado das mãos ao som da música "Ainsi font, font, font, les petites marionnettes" pode ser comparado, em nossa cultura, com o da canção "Tra-lá, tra-lá, tra-lá-lá-lá...”.

6. Segundo a escala Préaut (Prevenção de Autismo) (Laznik, 2006). Esta escala nos permite detectar, de maneira precoce, traços de risco de autismo em bebês a partir dos 4 meses de idade, sem, contudo, propor um diagnóstico fechado da patologia do autismo, visto que o fechamento de tal diagnóstico não pode ser feito antes da idade de 3 anos.

7. Trata-se de um protocolo que permite mensurar e analisar, a partir de 43 indicadores avaliados numa escala de 1 a 5 , a qualidade do comportamento dos bebês entre 2 e 36 meses, o grau de investimento dos pais e 
a qualidade das trocas interativas da dupla pais-bebês. Tais indicadores contemplam o grau de sensibilidade (sensitivity), movimentos de intrusão (intrusiveness) e a capacidade de impor limites (limit setting) dos pais, o grau de engajamento (involvement), movimentos de recusa (withdrawal) e de complacência (compliance) da criança e o nível de reciprocidade (reciprocity) e de trocas negativas (negative states) entre a díade. Todas as CIB da pesquisa PILE eram analisadas pela psicóloga clínica Christelle Viodé.

8. Entonação particular da voz materna quando ela se dirige ao seu bebê com uma voz melódica, enfatizando a acentuação e o prolongamento da última sílaba de cada palavra.

9. Este estudo foi realizado com auxílio de um programa chamado Eudico Linguistic Annotator (ELAN), que permite analisar, em milésimos de segundos, as imagens filmadas.

10. Esta avaliação foi feita pelo teste projetivo Mallette Projective de la Première Enfance (MPPE) (Roman,2005), único teste adaptado à primeira infância, que permite avaliar os aspectos psicodinâmicos da criança por meio da análise minuciosa da construção do seu brincar simbólico.

camila_saboia@hotmail.com Rua Canário, 917/182 04521-004 - São Paulo - SP - Brasil.

Recebido em novembro/2014. Aceito em junho/2015. 